\title{
Clinical use of blinatumomab for B-cell acute lymphoblastic leukemia in adults
}

This article was published in the following Dove Press journal:

Therapeutics and Clinical Risk Management

25 August 2016

Number of times this article has been viewed

Kum Ja Lee'

Vivian Chow'

Ashley Weissman ${ }^{2}$

Sunil Tulpule 3

Ibrahim Aldoss ${ }^{4}$

Mojtaba Akhtari ${ }^{5}$

'Department of Clinical Pharmacy and Pharmaceutical Economics and Policy, University of Southern California, ${ }^{2}$ Department of Pharmacy, University of Southern California Norris Cancer Hospital, Los Angeles, CA, ${ }^{3}$ Department of Medicine, Raritan Bay Medical Center, Perth Amboy, $\mathrm{NJ},{ }^{4}$ Department of Hematology and Hematopoietic Cell Transplantation, City of Hope, Duarte, CA, ${ }^{5}$ Jane Anne Nohl Division of Hematology and Center for the Study of Blood Diseases, University of Southern California Norris Comprehensive Cancer Center, Los Angeles, CA, USA
Correspondence: Mojtaba Akhtari Jane Anne Nohl Division of Hematology and Center for the Study of Blood Diseases, University of Southern California Norris Comprehensive Cancer Center, I44I Eastlake Avenue, Norris Topping Tower 3463, MC 9172, Los Angeles, CA 90033-9172, USA

$\mathrm{Tel}+$ I 21332386539 II

Fax +I 2133238650060

Email makhtari@usc.edu
Abstract: Adults with relapsed or refractory B-cell acute lymphoblastic leukemia have a dismal prognosis with a short median overall survival that can be measured in months. Because most patients will have chemotherapy-resistant disease, allogeneic hematopoietic stem cell transplantation remains the only potentially curative treatment. Despite advances in current management, patients continue to have poor outcomes and lack of durable responses. Thus, new therapies with alternative modes of actions are currently being investigated. Blinatumomab is a novel bispecific T-cell engager that simultaneously binds CD3-positive cytotoxic T-cells and CD19-positive B-cells, resulting in selective lysis of tumor cells. It has shown promising results in patients with relapsed or refractory acute lymphoblastic leukemia or those achieving hematologic response with persistent minimum residual disease. Future clinical trials will answer questions regarding its optimal place in the treatment paradigm. Dose-limiting toxicities include immunological toxicities and cytokine release syndrome. However, most patients tolerate the therapy relatively well. This review will focus on the pharmacology, clinical efficacy, and safety of blinatumomab in the treatment of adult B-cell acute lymphoblastic leukemia while highlighting its unique drug warnings and toxicity management.

Keywords: ALL, relapsed/refractory, BiTE, Blincyto

\section{Introduction}

Acute lymphoblastic leukemia (ALL) is an aggressive hematologic malignancy characterized by highly proliferative immature lymphoid cells in the bone marrow and peripheral blood. In addition to suppressing normal hematopoiesis, leukemic cells often spread to the lymph nodes, spleen, liver, central nervous system (CNS), and other organs. Due to improved diagnostic tests and procedures, ALL can be classified into different subgroups, including B- or T-cell precursor, Philadelphia chromosome $(\mathrm{Ph})$-positive or -negative, and various cytogenetic and molecular characteristics. Such unique ALL subclassification has often been translated into highly specific therapies. ${ }^{1}$

The age-adjusted incidence rate of ALL in the US is 1.7 per 100,000 persons per year. It is estimated that 6,590 new cases and 1,430 deaths will occur in $2016{ }^{2,3}$ Despite the low incidence, ALL is the most common malignancy in children. Sixty percent of the cases occur in patients $<20$ years of age with the median age of diagnosis being 14 years. In comparison, ALL is relatively uncommon in adults, with an occurrence rate of $25 \%$ in patients 45 years or older and only $11 \%$ in patients 65 years or older., The precursor B-cell subtype is the predominant form of ALL accounting for $\sim 80 \%$ of all cases of the disease. ${ }^{5}$

The prognosis of ALL, as measured by the complete response (CR) rate, duration of remission, and long-term survival, is influenced by many factors. In particular, the 
patient's age, white blood cell count at the time of diagnosis, B- or T-cell lineage, cytogenetic mutations, and response to induction therapy have all been identified as important prognostic factors. Identification of these factors allows the clinician to tailor treatment according to risk of disease recurrence. Patients older than 35 years or with an elevated white blood cell count of $>30 \times 10^{9} / \mathrm{L}$ at diagnosis are initially identified as high risk, whereas all others are classified as standard risk. ${ }^{5,6}$ Thus, a more intensive chemotherapy may be offered to high-risk patients who are unlikely to respond well to standard therapy. A delayed time to CR as well as the persistence of minimal residual disease (MRD) after induction therapy is associated with frequent relapse and poor outcome. ${ }^{6,7}$

The current treatment approach to ALL is one of the most highly intensive and complex programs in cancer therapy. Several chemotherapy regimens are considered appropriate to use as first-line therapy in adults for $\mathrm{Ph}$ negative ALL, including the Cancer and Leukemia Group B 8811, Eastern Cooperative Oncology Group 2993, and fractionated cyclophosphamide plus vincristine, doxorubicin, and dexamethasone. ${ }^{5-7}$ For adolescents and young adult patients aged 15-39 years, treatment is based on pediatricinspired protocols modified from the Berlin-FrankfurtMunster group. These aggressive treatment regimens have resulted in CR rates between 74\% and 93\% in adult ALL. Unfortunately, a subset of patients becomes refractory to the treatment and many others relapse. Consequently, the 5-year long-term survival rates in adults with B-cell ALL remain low: $54 \%$ and $28 \%$ for standard risk and high risk subgroups, respectively. ${ }^{6}$

Although there is no standard approach to care, the treatment for relapsed or refractory (R/R) adult ALL depends on the timing of relapse. If disease relapse occurs $>2$ years following initial treatment, reinduction with a regimen similar to that used in the frontline may be effective. In contrast, patients with primary resistant disease or relapse during induction chemotherapy should be treated with alternative agents, which may include combination regimens containing fludarabine, clofarabine, etoposide, ifosfamide, or mitoxantrone. ${ }^{5,8}$ However, these patients are at risk for cumulative morbidity from treatment toxicities, as well as a higher probability of cross-resistance to available chemotherapy agents. Therefore, the prognosis for patients who relapse after such intensive treatment is particularly poor. Remission is only achieved by $25 \%$ to $45 \%$ of patients and the overall survival is dismal, $5 \%$ to $8 \%$ at 5 years. ${ }^{9}$ Thus, research in new treatment options is warranted to improve outcomes in patients with $\mathrm{R} / \mathrm{R}$ adult ALL. Blinatumomab (Blincyto $^{\circledR}$, Amgen Inc., Thousand Oaks, CA, USA) is a bispecific CD19-directed CD-3 T-cell engager that has produced durable responses in patients with various B-cell malignancies, prompting an approval as a breakthrough therapy by the US Food and Drug Administration (FDA) in December 2014. ${ }^{10}$ This review will focus on the pharmacology, clinical results, and safety of blinatumomab. The management of immunological toxicities and challenges involved with its administration will also be discussed.

\section{Pharmacology Mechanism of action}

Blinatumomab (derived from "B lineage-specific antitumor mouse monoclonal antibody") is a first-in-class bispecific $\mathrm{T}$-cell engager antibody construct with dual binding specificities. It weighs $50 \mathrm{kDa}$, about a third the size of a typical monoclonal antibody. Its innovative mechanism of action uses patients' own cytotoxic T-cells to attack malignant B-cells.

The advanced antibody has an anti-CD3 arm to engage CD3-expressing T-cells and an anti-CD19 arm to bind to lymphoblasts expressing the CD19 marker (Figure 1). ${ }^{11}$ CD19 is solely expressed on the surface of both normal and malignant B-cells making it a reliable target for immunotherapy of B-cell ALL. ${ }^{5}$ Its variable domains are joined into a single-chain antibody by a small nonimmunogenic linker protein which confers greater rotational flexibility than other known antibodies. This unique feature of blinatumomab allows circulating T-cells to come in close proximity with malignant B-cells simultaneously binding to two epitopes positioned on cell membranes of two separate cells, thereby facilitating T-cell-mediated killing of the bound malignant B-cells. Thus, its antitumor activity is polyclonal in nature and does not require either $\mathrm{T}$-cell receptor specificity or major histocompatibility complex class 1 molecules on the surface of antigen presenting cells for activation. CD8- and CD4-positive effector memory T-cells have been shown to mediate the majority of bispecific T-cell engager activitiy. ${ }^{11-13}$

In vitro studies demonstrated that the binding between $\mathrm{T}$-and B-cells results in an immune synapse that leads to upregulation of T-cell markers CD2, CD25, CD69, as well as transient release of inflammatory cytokines, such as interferon-gamma, tumor necrosis factor-alpha, interleukin (IL)-2, IL-6, and IL-10. These activated T-cells induce perforin-mediated cytotoxicity via granzyme entry into the ALL blasts, 


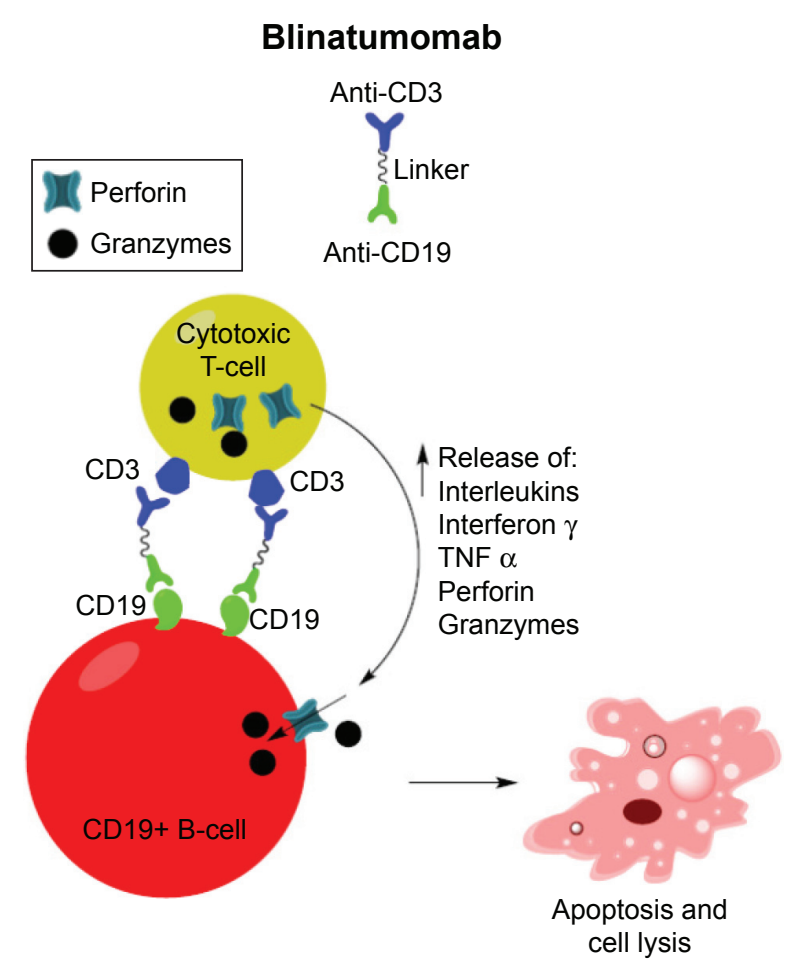

Figure I Blinatumomab structure and mechanism of action. Abbreviation: TNF $\alpha$, tumor necrosis factor alpha.

resulting in apoptosis and cell lysis. It is hypothesized that blinatumomab also causes marked polyclonal T-cell proliferation with serial lysis of CD19-positive target cells. The antibody preferentially binds to CD19 as compared to $\mathrm{CD} 3$ as indicated by the higher binding affinity to B- versus T-cells with an equilibrium dissociation constant of $1.6 \times 10^{-9}$ versus $8.7 \times 10^{-8} \mathrm{M}$, respectively. The relatively low affinity for $\mathrm{CD} 3$ on T-cells may allow fast release of T-cells from target B-cells after lysis enabling them to bind to additional target B-cells. ${ }^{11-13}$

\section{Immunopharmacology}

The immunopharmacological studies of blinatumomab focused primarily on the evaluation of dynamic changes to B-cells, T-cells, and cytokines during the treatment in a defined population of MRD-positive ALL patients. Cellular behaviors were highly predictable at initiation and during the continuous intravenous (CIV) infusion of blinatumomab in 21 adult ALL patients in hematologic remission but molecular relapse. ${ }^{12}$ Peripheral B-cells decreased to below detection limit at a mean of 2.18 days and did not improve throughout blinatumomab treatment suggesting continued activity via the redirected lysis of CD19-positive target cells. On the other hand, peripheral T-cells reached a nadir within 0.36 days, recovered to baseline in 8 to 9 days, and continued to increase to a mean of $220 \%$ of baseline in all but one patient during the first cycle of treatment. This trend was hypothesized to be an initial redistribution of T-cells due to adhesion to endothelium and subsequent activation and proliferation of T-cells. Release of cytokines, such as IL-10, IL-6, and interferon-gamma, occurred within the first 48 hours and declined rapidly during the first cycle of blinatumomab, but was not detected with the second cycle of treatment. Interestingly, this pattern of B-cell depletion, T-cell expansion, and cytokine release was similar between MRD responders and nonresponders. The effect of blinatumomab on immunoglobulin (Ig) levels was reported in a subset of six patients who did not receive allogeneic hematopoietic stem cell transplantation (alloHSCT) ${ }^{14}$ Five of these patients were MRD responders, and the IgM, IgA, and IgG levels reached the lowest levels of $12 \%, 6 \%$, and $29 \%$ of baseline with a median time to nadir of 126,168 , and 260 days, respectively. In the MRD nonresponders, the IgG level was not affected by blinatumomab treatment. The recovery of $\operatorname{IgG}$ and $\operatorname{IgA}$ levels was slower than IgM, suggesting a delayed recovery of plasma cells and memory B-cells compared to IgM-secreting naïve B-cells after blinatumomab treatment.

\section{Pharmacokinetics and dosage}

The main pharmacokinetic studies were derived according to a 4-week CIV administration with a 2-week break between cycles in adult patients. Blinatumomab demonstrates linear pharmacokinetics over a dose range of 5 to $90 \mu \mathrm{g} / \mathrm{m}^{2} /$ day intravenous (IV) infusion. The increase in mean steady-state serum concentration $\left(C_{\mathrm{ss}}\right)$ was proportional to the dose change in this range. The $C_{\mathrm{ss}}$ was achieved within 1 day and remained stable during the entire infusion period. Clinical doses of 5 and $15 \mu \mathrm{g} / \mathrm{m}^{2} /$ day administered by CIV resulted in the mean $C_{\mathrm{ss}}$ of 211 and $621 \mathrm{pg} / \mathrm{mL}$, respectively. Doses $\geq 15 \mu \mathrm{g} / \mathrm{m}^{2} /$ day achieved an in vivo $C_{\mathrm{ss}}$ of $600 \mathrm{pg} / \mathrm{mL}$, a level that is above the in vitro biological relevant concentration (EC90) for CD19-positive B leukemia cell lines of $470 \mathrm{pg} / \mathrm{mL}$. These doses also correspond to clinical responses to blinatumomab seen in non-Hodgkin's lymphoma and in R/R ALL studies and associated with the lowest rate of adverse effects. ${ }^{15-17}$ The mean volume of distribution, elimination half-life, and systemic clearance of blinatumomab are estimated as $4.52 \mathrm{~L}, 2.11$ hours, and $2.92 \mathrm{~L} /$ hour, respectively. The volume of distribution and systemic clearance of blinatumomab are highly variable with coefficient of variation of $65 \%$ and $97 \%$, respectively. The clearance of unchanged drug by the kidneys is negligible indicating limited renal 
excretion. Blinatumomab is believed to be degraded into small peptides and amino acids via catabolic pathways, but its specific metabolism has not been characterized. ${ }^{15}$ Its short half-life is possibly due to the small molecular mass and lack of Fc domain. ${ }^{12}$ Thus, continuous infusion is necessary to maintain therapeutic drug concentrations in the blood.

Interestingly, the clearance of blinatumomab in adults is not affected by body size. The mean $C_{\mathrm{ss}}$ values are similar when the body surface area-based dosing (initial $5 \mu \mathrm{g} / \mathrm{m}^{2}$ / day and increasing to $15 \mu \mathrm{g} / \mathrm{m}^{2} /$ day) and fixed dosing (initial $9 \mu \mathrm{g} /$ day and increasing to $28 \mu \mathrm{g} /$ day) are used. Furthermore, drug clearance in adult patients is not affected by age or sex. ${ }^{16,18}$ The final FDA-approved dose of blinatumomab is 9 $\mu \mathrm{g} /$ day on days $1-7$ of the first cycle, followed by $28 \mu \mathrm{g} /$ day on days 8-28 via CIV infusion. After a 2-week treatment-free period, subsequent cycles can be initiated at $28 \mu \mathrm{g} /$ day for the entire cycle. Patients who achieve complete remission or partial hematological recovery in the first two cycles can receive up to three additional cycles (Table 1$).{ }^{17}$

\section{Clinical efficacy in adult ALL}

Results from three clinical trials have been published on the use of blinatumomab in adult ALL (Table 2). A Phase II single arm, multicenter trial in Germany by the German Multicenter Study Group for Adult Acute Lymphoblastic Leukemia enrolled patients with precursor B-cell ALL who were in hematologic remission but were either molecularly refractory or had molecular relapse with MRD.${ }^{17}$ Blinatumomab was administere as 6 -week cycles of $15 \mu \mathrm{g} / \mathrm{m}^{2} /$ day CIV infusion for 4 weeks followed by 2 weeks off. Patients who achieved MRD negativity could receive additional three cycles of consolidation treatment, as well as alloHSCT if eligible. Out of 20 evaluable patients, 15 (75\%) patients had never achieved MRD negativity, and five (25\%) patients were $\mathrm{Ph}$-positive and refractory to imatinib or dasatinib. Sixteen of
20 evaluable patients (80\%) achieved the primary endpoint of MRD negativity within 4 weeks of treatment, including 12 patients with molecularly refractory disease and three Ph-positive patients. The median relapse-free survival (RFS) probability at 33 months follow-up was $61 \%$. Patients who achieved MRD negativity had an RFS of 19.1 months compared to 3.2 months in MRD nonresponders. ${ }^{19}$ Nine (43\%) patients eventually received alloHSCT, six of whom were still in complete remission at 33 months. Of the eleven MRD responders who did not undergo alloHSCT, four patients remained in hematologic and molecular CR and two patients were in ongoing hematologic CR at 30 months follow-up. These results suggested MRD negativity induced with blinatumomab led to long duration of CR and prolonged RFS.

Promising results from adult ALL patients with MRD led to the study of blinatumomab as salvage therapy in patients with R/R ALL. A Phase II single arm, multicenter trial by German Multicenter Study Group for Adult Acute Lymphoblastic Leukemia included patients with precursor B-cell ALL with $>5 \%$ bone marrow blasts who were refractory to induction therapy or had relapsed after induction, consolidation, or alloHSCT. ${ }^{15}$ The initial dosefinding phase identified the 6-week cycle of blinatumomab with the best tolerability profile as $5 \mu \mathrm{g} / \mathrm{m}^{2} /$ day CIV for 1 week, then $15 \mu \mathrm{g} / \mathrm{m}^{2} /$ day CIV for 3 weeks, and then 2 weeks off. Subsequent cycles of treatment were initiated at the higher dose of $15 \mu \mathrm{g} / \mathrm{m}^{2} /$ day CIV for 4 weeks. This dosing regimen was used in the extension phase in which patients received two cycles of blinatumomab, followed by up to three cycles of consolidation or until alloHSCT. Intrathecal chemotherapy for CNS relapse prophylaxis was administered with each cycle. A total of 36 patients were enrolled, of whom three $(8 \%)$ had primary refractory disease, eleven $(31 \%)$ at first relapse, seven (19\%) at second or later relapse, and 15 (42\%) had relapsed after

Table I Drug summary of blinatumomab in relapsed/refractory ALL

\begin{tabular}{|c|c|}
\hline Drug name & Blinatumomab; Blincyto ${ }^{\circledR}$ (Amgen Inc., Thousand Oaks, CA, USA) \\
\hline Drug class & Bispecific T-cell engager antibodies \\
\hline Mechanism of action & Simultaneously binds CD3-positive cytotoxic T-cells and CDI9-positive B-cells, resulting in direct lysis \\
\hline \multirow[t]{2}{*}{ Dosage and route of administration } & Cycle I: $9 \mu \mathrm{g} /$ day CIV infusion $\times \mathrm{I}$ week, then $28 \mu \mathrm{g} /$ day $\mathrm{CIV} \times 3$ weeks, then 2 weeks off \\
\hline & Cycle $2+: 28 \mu \mathrm{g} /$ day $\mathrm{CIV} \times 4$ weeks, then 2 weeks off \\
\hline \multirow[t]{4}{*}{ Pharmacokinetics, estimated mean } & $C_{\mathrm{ss}}: 211 \mathrm{pg} / \mathrm{mL}$ at $9 \mu \mathrm{g} / \mathrm{day} ; 621 \mathrm{pg} / \mathrm{mL}$ at $28 \mu \mathrm{g} / \mathrm{day}$ \\
\hline & $T_{1 / 2}: 2.11$ hours \\
\hline & CL: $2.92 \mathrm{~L} / \mathrm{h}$ \\
\hline & $V_{z}: 4.52 \mathrm{~L}$ \\
\hline Development phase & Phase III \\
\hline FDA approval date & December 3, 2014 under accelerated approval \\
\hline Approved indication & Treatment of Philadelphia chromosome-negative relapsed or refractory B-cell precursor ALL \\
\hline
\end{tabular}

Abbreviations: ALL, acute lymphoblastic leukemia; CIV, continuous intravenous; $\mathrm{CL}$, systemic clearance; $C_{\mathrm{ss}}$, steady-state serum concentration; FDA, US Food and Drug Administration; $T_{1 / 2}$, elimination serum half-life; $V_{z}$, distribution volume. 
Table 2 Summary of blinatumomab efficacy in adult B-cell ALL

\begin{tabular}{|c|c|c|c|}
\hline Study & Patient population & Blinatumomab dose & Outcomes measures \\
\hline $\begin{array}{l}\text { Phase II, single } \\
\text { arm, multicenter } \\
\text { in Germany } \\
\text { Adult B-ALL in } \\
\text { hematologic CR, } \\
\text { but molecular } \\
\text { refractory or } \\
\text { with MRD }{ }^{17,19}\end{array}$ & $\begin{array}{l}\mathrm{N}=20 \text { evaluable patients } \\
\text { - Median age }=47 \\
\text { - Five patients with } \mathrm{Ph}+\text { disease } \\
\text { refractory to imatinib } \\
\text { and/or dasatinib } \\
\text { - No prior allogeneic HSCT }\end{array}$ & $\begin{array}{l}\text { Continuous infusion: } \\
15 \mu \mathrm{g} / \mathrm{m}^{2} / \text { day for } \\
4 \text { weeks, then } 2 \text { weeks off }\end{array}$ & $\begin{array}{l}\text { Primary outcome: } \\
\text { I6/20 (80\%) achieved MRD negativity } \\
\text { within } 4 \text { weeks, of which: } \\
\text { - Three patients (out of five) were Ph+ } \\
\text { - Nine patients proceeded to allogeneic } \\
\text { HSCT } \\
\text { At } 33 \text { months: } \\
\text { - RFS } 61 \% \text { for all patients } \\
\circ 19.1 \text { months in responders } \\
\text { - } 3.2 \text { months in nonresponders } \\
\text { - Nine patients post allogeneic HSCT } \\
\text { - Six in hematologic CR } \\
\circ \text { Two relapses } \\
\text { One TRM } \\
\text { - Eleven patients w/o allogeneic HSCT } \\
\text { - Six in hematologic CR } \\
\text { (two patients were Ph+ on TKI) } \\
\text { - Four relapses }\end{array}$ \\
\hline $\begin{array}{l}\text { Phase II, single } \\
\text { arm, multicenter } \\
\text { in Germany } \\
\text { Adult R/R } \\
\text { B-ALL } 15,20\end{array}$ & $\begin{array}{l}\mathrm{N}=36 \text { evaluable patients } \\
\text { - Median age }=32 \\
\text { - }>5 \% \text { blast in bone marrow } \\
\text { - } \mathrm{Ph}+\text { patients excluded } \\
\text { - No history of or active } \\
\mathrm{CNS} \text { disease } \\
\text { - } \mathrm{I} 5 \text { patients ( } 42 \% \text { ) had prior } \\
\text { allogeneic HSCT }\end{array}$ & $\begin{array}{l}\text { Dose used after } \\
\text { dose-finding phase, } \\
\text { continuous infusion: } \\
5 \mu \mathrm{g} / \mathrm{m}^{2} / \text { day } \times \text { I week, then } \\
15 \mu \mathrm{g} / \mathrm{m}^{2} / \text { day } \times 3 \text { weeks, } \\
\text { then } 2 \text { weeks off }\end{array}$ & $\begin{array}{l}\text { Primary outcome: } \\
\text { 25/36 ( } 69 \%) \text { achieved CR or CRh within } \\
\text { two treatment cycles: } \\
\text { - I5 patients }(42 \%) \text { with CR } \\
\text { - Ten patients }(28 \%) \text { with CRh } \\
\text { - Eight of I5 patients }(53 \%) \text { with } \\
\text { prior allogeneic HSCT achieved } \\
\text { CR/CRh } \\
\text { Secondary outcomes: } \\
\text { - } 22 / 25 \text { ( } 88 \%) \text { achieved MRD negativity } \\
\text { - I3/25 (52\%) responders proceeded } \\
\text { to allogeneic HSCT } \\
\circ \text { Two relapses } \\
\text { - Six TRM } \\
\text { - I2/25 did not proceed to allogeneic } \\
\text { HSCT } \\
\text { - Eight relapses } \\
\text { At median follow-up of } 28.9 \text { months } \\
\text { - Median RFS }=8.8 \text { months } \\
\text { - Median OS = } 9.8 \text { months }\end{array}$ \\
\hline $\begin{array}{l}\text { Phase II, single } \\
\text { arm, multicenter } \\
\text { in Europe } \\
\text { and US } \\
\text { Adult R/R } \\
\text { B-ALL'I }\end{array}$ & $\begin{array}{l}\mathrm{N}=189 \text { evaluable patients } \\
\text { - Median age }=39 \\
\text { - } \geq 10 \% \text { blast in bone marrow } \\
\text { - } \mathrm{Ph}+\text { patients excluded } \\
\text { - No history of or active } \\
\text { CNS disease } \\
\text { - } 64 \text { patients ( } 34 \%) \text { had prior } \\
\text { allogeneic HSCT }\end{array}$ & $\begin{array}{l}\text { Continuous infusion: } \\
9 \mu \mathrm{g} / \text { day } \times \text { I week, then } \\
28 \mu \mathrm{g} / \mathrm{day} \times 3 \text { weeks, then } \\
2 \text { weeks off. Cycle } 2 \text { and } \\
\text { on: } 28 \mu \mathrm{g} / \mathrm{day} \times 4 \text { weeks, } \\
\text { then } 2 \text { weeks off }\end{array}$ & 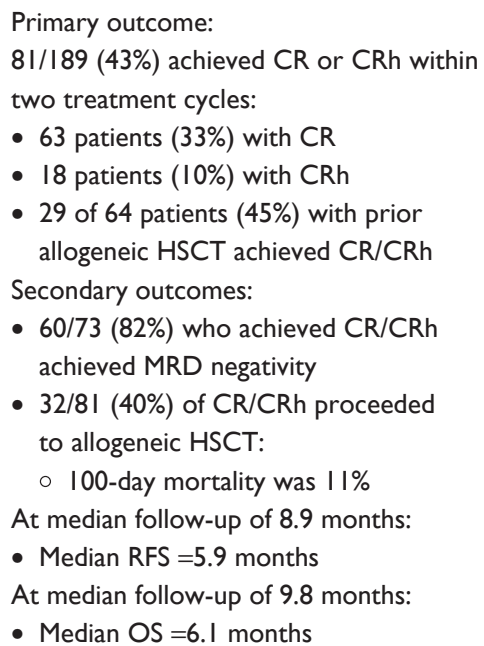 \\
\hline
\end{tabular}

Abbreviations: ALL, acute lymphoblastic leukemia; B-ALL, B-cell ALL; CNS, central nervous system; CR, complete response; CRh, CR with incomplete hematologic recovery; HSCT, hematopoietic stem cell transplantation; mAB, monoclonal antibody; MRD, minimal residual disease; OS, overall survival; Ph, Philadelphia chromosome; RFS, relapse-free survival; R/R, relapsed or refractory; TKI, tyrosine kinase inhibitor; TRM, transplant related mortality. 
alloHSCT. The primary endpoint was the proportion of patients with CR or partial hematologic recovery (CRh with platelet $>50,000 / \mu \mathrm{L}$, hemoglobin $>7 \mathrm{~g} / \mathrm{dL}$, and absolute neutrophil count $>500 / \mu \mathrm{L})$ within two cycles. Overall, $25(69 \%)$ patients reached the primary endpoint; $15(42 \%)$ patients achieved CR, and ten (28\%) patients achieved CRh within two cycles of blinatumomab, including eight patients who had relapsed after prior alloHSCT. Of the 25 patients in remission, 22 (88\%) patients became MRD-negative and $13(52 \%)$ patients were able to proceed to alloHSCT. At median follow-up of 28.9 months, the median RFS was 8.8 months, and overall survival was 9.8 months. ${ }^{20}$ Ten (40\%) patients eventually had disease relapse, eight of whom did not receive alloHSCT after blinatumomab-induced remission.

A larger Phase II, single arm, open label, global multicenter trial was conducted to evaluate the efficacy of blinatumomab in patients with R/R ALL. ${ }^{21}$ It included patients with $\geq 10 \%$ bone marrow blasts who had primary refractory disease, RR disease after salvage therapy, or had relapsed within 12 months of first remission or alloHSCT. Only Phnegative patients were included. Similar to previous studies, the study excluded patients with extramedullary or CNS involvement of ALL, chronic infection (eg, HIV), autoimmune disease, history of autologous HSCT or monoclonal antibody therapy within 6 weeks, exposure to chemotherapy and immunotherapy within 4 weeks, and systemic treatment of graft-versus-host disease within 2 weeks. A prephase treatment with dexamethasone was allowed for patients with high tumor burden to reduce risk of cytokine release syndrome (CRS). A fixed, nonweight-based dosing of blinatumomab was utilized for cycle 1: $9 \mu \mathrm{g} /$ day CIV for 1 week, then $28 \mu \mathrm{g} /$ day CIV for 3 weeks, then 2 weeks off, with future cycles initiated without the stepwise increase at $28 \mu \mathrm{g} /$ day CIV for 4 weeks. After two cycles of induction therapy, patients could receive up to three cycles of consolidation or proceed to alloHSCT if a donor was available. A total of 189 patients were enrolled, with a median age of 39 years and were mostly male (63\%). Patients had primary refractory disease $(20 \%)$ or were heavily pretreated with one (41\%), two $(22 \%)$, or more than two $(17 \%)$ lines of salvage therapies. Sixty-four (34\%) patients had relapsed after prior alloHSCT, and $130(69 \%)$ patients had $\geq 50 \%$ bone marrow blasts at time of enrollment. Out of 189 patients, 81 (43\%) patients reached the primary endpoint of $\mathrm{CR} / \mathrm{CRh} ; 63$ (33\%) patients achieved CR and $18(10 \%)$ patients achieved CRh within two cycles of blinatumomab. Of the responders, 59 (73\%) patients also became MRD-negative by the end of cycle 1 treatment and a total of $60(82 \%)$ of patients became MRD-negative by the end of cycle 2. Baseline characteristics, such as sex, age group, number of salvage therapies, and history of alloHSCT, were not different between $\mathrm{CR} / \mathrm{CRh}$ responders and nonresponders. However, a higher proportion of patients with $<50 \%$ bone marrow blasts achieved CR/CRh compared to patients with $\geq 50 \%$ bone marrow blasts ( $73 \%$ vs $29 \%$ ). Secondary endpoints of median RFS were 5.9 months and median overall survival was 6.1 months, at median follow-up time of 8.9 and 9.8 months, respectively. Patients who achieved MRD negativity had an RFS of 6.9 months and overall survival of 11.5 months compared with MRD nonresponders of an RFS of 2.3 months and overall survival of 6.7 months. Out of the 81 patients who achieved remission, $32(40 \%)$ patients were able to proceed to alloHSCT, including five patients who had relapsed disease after a prior alloHSCT. The estimated posttransplant 100-day mortality in these patients was $11 \%$. Although essentially all patients (99\%) reported adverse events of any grade, most signs and symptoms were transient and manageable by supportive care measures. Blinatumomab was shown to be effective in inducing hematologic and molecular remission in poor risk, heavily pretreated patients with R/R ALL, allowing eligible patients to undergo potentially curative alloHSCT.

\section{Adverse drug events}

The side effect profile of blinatumomab is quite unique and consistent with its mechanism of action. The most significant toxicities noted in the studies were CRS and CNS events. ${ }^{15,17,21}$ Common adverse drug events include cytopenia, infection, and other laboratory abnormalities. It was noted that most events developed in the first days of the first cycle of treatment and were transient.

CRS is mediated by the release of proinflammatory cytokines IL-10, IL-6, and interferon-gamma after rapid lysis of tumor cells by activated T-cells, which typically happens during the first days of the first blinatumomab infusion. ${ }^{12}$ Reactions are mostly mild flu-like symptoms, such as pyrexia, chills, and myalgia, but may include more serious conditions, such as hypotension, capillary leak syndrome, pulmonary edema, and even multiorgan failure. In some cases, this rapid cytokine release can even trigger hemophagocytic lymphohistiocytosis and macrophage activation syndrome, which are disorders of abnormal immune system activation characterized by high fever, splenomegaly, hyperferritinemia, hypertriglyceridemia, coagulopathy, and progressive cytopenias. ${ }^{22}$ The most frequent toxicity reported in the studies is pyrexia, with an incidence rate of $81 \%$ (grade $1 / 2,75 \%$; grade $3,6 \%$ ) in one small Phase II 
study and $60 \%$ in the larger confirmatory Phase II trial. ${ }^{15,21}$ However, severe CRS was uncommon: grade 4 CRS in two out of 36 patients $(6 \%)$ and grade 3 CRS in three out of 189 patients $(2 \%){ }^{15,21}$ This low rate of CRS observed in the larger study was attributed to the stepwise dosing of blinatumomab and required prephase treatment with dexamethasone $10-24 \mathrm{mg} / \mathrm{m}^{2} /$ day (5 days maximum) in patients with high leukemic burden or rapidly progressing disease.

Blinatumomab-associated CNS toxicity may be caused by activated T-cells binding CD19-positive B-cells in the CNS, resulting in rapid neurotoxic cytokine release and disruption of the blood-brain barrier. ${ }^{11,21,23}$ Symptoms of CNS adverse events may include encephalopathy, seizure, tremor, aphasia, and disorientation, which are reversible in most cases. Onset of symptoms usually occurred around the seventh day of the first cycle of treatment. ${ }^{21}$ In one Phase II trial, blinatumomab was permanently discontinued in one patient due to a grade 3 seizure, which fully resolved within 1 day after stopping the infusion. ${ }^{17}$ In another Phase II study, common CNS toxicities included fatigue (50\%), headache $(47 \%)$, and tremor (36\%). ${ }^{15}$ Treatment was interrupted in six patients (17\%) who experienced CNS events, such as encephalopathy, epilepsy, or convulsions. All events resolved within 72 hours of infusion interruption. Four patients later successfully completed treatment while two patients with encephalopathy discontinued treatment permanently due to exacerbated recurrence of symptoms. In a large confirmatory Phase II trial, 98 out of 189 patients $(52 \%)$ had neurologic events, which were mostly grade 1 or 2 during cycle $1 .^{21}$ These symptoms were managed with dexamethasone and did not require blinatumomab interruption. Twenty patients (11\%) had grade 3 neurologic events while four patients $(2 \%)$ had grade 4 events. No fatal CNS toxicity occurred.

Additionally, infection was commonly reported in all clinical trials. ${ }^{15,17,21}$ Approximately 25\% of the patients studied experienced serious infections, such as sepsis, pneumonia, bacteremia, and catheter-site infections. ${ }^{16}$ All four reported drug-related deaths were associated with infection, including cases of fungal infections and sepsis. ${ }^{17,21}$

Other frequent toxicities with blinatumomab include cytopenias and various laboratory abnormalities, such as transaminitis and hypogammaglobulinemia. While decrease in blood Ig with blinatumomab has been reported, its correlation with infection rate has not been studied. ${ }^{17,18}$ Baseline and periodic monitoring of Ig levels, as well as IgG replacement therapy in patients with severe infections and low serum IgG concentrations, may be considered. ${ }^{14}$ The most common grade 3/4 hematologic events were lymphopenia, leukopenia, thrombocytopenia, febrile neutropenia, and anemia.

Although not common, disseminated intravascular coagulation was a rare but serious adverse event reported. In a large Phase II trial, it occurred in four out of 189 patients $(2 \%) .{ }^{21}$

\section{Important safety considerations}

There are many warnings and precautions associated with blinatumomab treatment. Drug labeling includes two boxed warnings: CRS and neurotoxicities ${ }^{17}$ Additionally, an FDArequired risk evaluation and mitigation strategy mandates a communication plan to health care providers emphasizing these boxed warnings as well as the potential for errors in drug preparation and administration. While most patients tolerate the infusion fairly well, dose-limiting toxicities, including CRS and CNS events, may need to be managed by treatment interruption or discontinuation (Table 3 ).

\section{CRS}

Mild manifestations of CRS may be indistinguishable from infusion reactions, and can be managed with dexamethasone. However, grade 3/4 events require blinatumomab infusion interruption. ${ }^{16}$ Another treatment strategy is to inhibit the proinflammatory response caused by cytokine release. In a case report of a 7-year-old male on a Phase I dose-escalation trial who received blinatumomab at a dose of $30 \mu \mathrm{g} / \mathrm{m}^{2} /$ day, life-threatening CRS occurred and was associated with hemophagocytic lymphohistiocytosis/macrophage activation syndrome. He continued to deteriorate after dexamethasone treatment and blinatumomab discontinuation. This severe reaction was rapidly reversed by one $8 \mathrm{mg} / \mathrm{kg}$ dose of tocilizumab, an IL-6 receptor antagonist, and it did not seem to inhibit the efficacy of blinatumomab. ${ }^{22}$

While there are some treatment techniques, reduction of CRS risk was inherently designed by the stepwise dosing schedule of blinatumomab at $9 \mu \mathrm{g} /$ day for 1 week, followed by $28 \mu \mathrm{g} /$ day for 3 weeks. ${ }^{21}$ Additionally, the required premedication with dexamethasone helps prevent CRS as well as infusion related reactions. Moreover, CRS incidence and intensity may be associated with baseline disease burden. ${ }^{21}$ To reduce the development of severe CRS, two clinical trials implemented prephase treatment with dexamethasone with or without cyclophosphamide for patients with high tumor load or rapidly progressing disease..$^{15,21}$

\section{Neurotoxicity}

While there have not been any fatal CNS-related events reported yet, neurotoxicity is the reason for most infusion 
Table 3 Manufacturer guidelines for blinatumomab toxicity management

\begin{tabular}{|c|c|c|}
\hline Toxicity $^{a}$ & Signs/symptoms & Management recommendation \\
\hline \multicolumn{3}{|c|}{ Cytokine release syndrome } \\
\hline Grade 3 & $\begin{array}{l}\text { Prolonged symptoms not responding to initial } \\
\text { infusion interruption, high dose or multiple } \\
\text { vasopressors required }\end{array}$ & $\begin{array}{l}\text { Interrupt infusion until resolved to less than } \\
\text { grade I for } 3 \text { days, then restart at } 9 \mu \mathrm{g} / \text { day. }\end{array}$ \\
\hline Grade 4 & $\begin{array}{l}\text { Life threatening symptoms, ventilator } \\
\text { support required }\end{array}$ & Discontinue infusion permanently. \\
\hline \multicolumn{3}{|c|}{ Neurological symptoms } \\
\hline Grade 3 & - & $\begin{array}{l}\text { During } 9 \mu \mathrm{g} / \text { day infusion: discontinue infusion permanently. } \\
\text { During } 28 \mu \mathrm{g} / \text { day infusion: interrupt infusion until resolved } \\
\text { to less than grade I for } 3 \text { days, then restart at } 9 \mu \mathrm{g} / \text { day. } \\
\text { If not resolved in } 7 \text { days, discontinue permanently. }\end{array}$ \\
\hline Grade 4 & - & Discontinue infusion permanently. \\
\hline Seizure & - & $\begin{array}{l}\text { If more than one episode, discontinue infusion } \\
\text { permanently. }\end{array}$ \\
\hline \multicolumn{3}{|c|}{ Hepatotoxicity } \\
\hline Grade 3 & $\begin{array}{l}\text { Bilirubin }>3 \times \text { upper limits of normal, or } \\
\text { AST/ALT }>5 \times \text { upper limits of normal }\end{array}$ & Interrupt infusion until resolved. \\
\hline \multicolumn{3}{|c|}{ 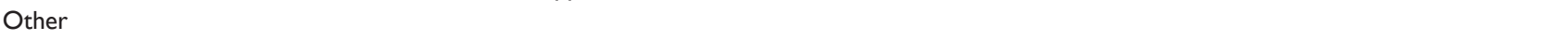 } \\
\hline Grade 3 & - & $\begin{array}{l}\text { Interrupt infusion until resolved to less than grade } \\
\text { I for } 3 \text { days, then restart at } 9 \mu \mathrm{g} / \text { day. If not resolved } \\
\text { in } 14 \text { days, discontinue permanently. }\end{array}$ \\
\hline Grade 4 & - & Discontinue infusion permanently. \\
\hline
\end{tabular}

Note: ${ }^{\mathrm{B}}$ Based on the Common Terminology Criteria for Adverse Events.

Abbreviations: ALT, alanine aminotransferase; AST, aspartate aminotransferase.

discontinuations. ${ }^{15,17,21}$ Management includes dexamethasone treatment, with or without blinatumomab interruption, and antiseizure medication as indicated. ${ }^{15,17,21}$ Patients who developed epilepsy or convulsions upon starting blinatumomab successfully resumed treatment with antiseizure prophylaxis medications. ${ }^{15}$ However, routine antiseizure prophylaxis for all patients is not required. Permanent discontinuation of blinatumomab is necessary if more than one seizure occurs during blinatumomab administration. ${ }^{16}$ Due to the potential for these severe neurologic events, a warning to avoid driving and operating heavy or potentially dangerous machinery has also been warranted.

\section{Infections}

Warnings for infection as well as febrile neutropenia have been issued. Institutional guidelines for monitoring and treatment of infections should be followed, including antibiotic use and surveillance cultures. Management of fever is best with acetaminophen and/or dexamethasone. ${ }^{21}$

\section{Tumor lysis syndrome}

Tumor lysis syndrome has been observed in patients receiving blinatumomab. Appropriate prophylactic measures, including adequate hydration and pretreatment cytoreduction, should be considered in patients receiving treatment, especially those with high leukemic burden. Grade 3 events warrant temporary infusion interruption while grade 4 events may lead to discontinuation. ${ }^{16}$

\section{Hepatotoxicity}

Transient elevations in liver enzymes, often observed in the setting of CRS, were documented with blinatumomab. Liver function tests must be monitored prior to the start of infusion as well as during treatment. Infusion interruption is warranted for transaminases greater than five times the upper limit of normal or bilirubin more than three times upper limit of normal. ${ }^{16}$

\section{Preparation and administration}

The preparation and administration of blinatumomab is an intricate multistep process that must be strictly followed to minimize errors. ${ }^{16}$ Careful aseptic technique is required to prevent contamination since the drug does not contain preservatives. During preparation, the blinatumomab-specific IV solution stabilizer is used to coat the prefilled diluent IV bag prior to addition of reconstituted drug. This step helps to prevent adhesion of drug to IV bag and lines. However, it is important to note that blinatumomab is reconstituted with sterile water for injection only, and not the IV solution stabilizer. Close attention to specific IV bag volumes must be followed. The final admixed volume will be more than the volume administered to the patient because it accounts for priming of the IV line to ensure the patient will receive the full dose of medication. 
Careful administration of blinatumomab is also very important. The treatment is administered as a CIV infusion through a dedicated lumen at a constant rate using an infusion pump. While a lockable ambulatory infusion pump may be used for most of the cycle, inpatient administration is recommended for the first 9 days of the first cycle and again for the first 2 days of the second cycle for close monitoring of adverse reactions. Thereafter, a home care provider or practitioner in the outpatient setting performs IV bag changes. To help prevent severe CRS, dexamethasone must be given prior to treatment initiation in each cycle, prior to the dose escalation in cycle 1 , and prior to any restart after 4 hours or more of infusion interruption. Furthermore, the infusion line should never be flushed when changing bags or at the completion of the infusion as this may cause medication overdose and increased adverse reactions. If this occurs, the infusion should be stopped while monitoring and providing supportive care to the patient. The infusion may be restarted once all toxicities have resolved and at least 12 hours after drug interruption.

\section{Conclusion}

Most adults with R/R and MRD-positive B-cell ALL have chemotherapy-resistant disease and thus a poor prognosis. This unsolved therapeutic problem drives the pursuit of novel drug classes, such as bispecific T-cell engager antibodies. Recent FDA approval of blinatumomab was granted after current data demonstrated promising clinical efficacy with manageable toxicity. However, the clinical application of blinatumomab in the treatment of adult ALL has not been entirely established. Results from a Phase II trial in $\mathrm{R} / \mathrm{R}$ patients with Ph-positive ALL are anticipated soon, which may demonstrate the utility of blinatumomab as secondline therapy for this patient population..$^{24} \mathrm{~A}$ Phase III study in adults with newly diagnosed Ph-negative B-cell ALL is being conducted to explore the potential of combining blinatumomab with chemotherapy in the first-line setting. ${ }^{25}$ Another Phase III trial is recruiting adults with $\mathrm{R} / \mathrm{R} \mathrm{Ph}$ negative B-cell ALL to compare blinatumomab to standard of care chemotherapy, including high dose cytarabine, high dose methotrexate, fludarabine- and clofarabine-based regimens. ${ }^{26}$ The primary outcome measure for both Phase III studies is overall survival. Findings from these ongoing trials and other investigations will define the role of blinatumomab and identify its optimal place in therapy.

\section{Disclosure}

The authors report no conflicts of interest in this work.

\section{References}

1. Jabbour EJ, Faderl S, Kantarjian HM. Adult acute lymphoblastic leukemia. Mayo Clin Proc. 2005;80:1517-1527.

2. National Cancer Institute. SEER cancer statistics review, 1975-2011: Leukemia, annual incidence rates (acute lymphocytic leukemia); Updated 2014. Available from: http://seer.cancer.gov/csr/1975_2011. Accessed January 19, 2016.

3. American Cancer Society. Cancer Facts and Figures, 2016. Atlanta, GA: American Cancer Society; 2016. Available from: http:// www.cancer.org/research/cancerfactsstatistics. Accessed January 19, 2016.

4. National Cancer Institute. SEER cancer statistics review, 1975-2011: Overview, median age at diagnosis; 2014. Available from: http://seer. cancer.gov/csr/1975_2011/. Accessed January 19, 2016.

5. NCCN Clinical Practice Guidelines in Oncology: Acute Lymphoblastic Leukemia. National Comprehensive Cancer Network. Version 1. 2016. Available from: https://www.nccn.org/professionals/physician_gls/ f_guidelines.asp. Accessed April 25, 2016.

6. Gökbuget N, Hoelzer D. Treatment of adult acute lymphoblastic leukemia. Semin Hematol. 2009;46:64-75.

7. Bassan R. Adult acute lymphoblastic leukaemia. Crit Rev Oncol Hematol. 2004;50:223-261.

8. Virchis A, Koh M, Rankin P, et al. Fludarabine, cytosine arabinoside, granulocyte-colony stimulating factor with or without idarubicin in the treatment of high risk acute leukaemia or myelodysplastic syndrome. Br J Haematol. 2004;124(1):26-32.

9. Bassan R, Hoelzer D. Modern therapy of acute lymphoblastic leukemia. J Clin Oncol. 2011;29(5):532-543.

10. FDA approves Blincyto to treat a rare form of acute lymphoblastic leukemia. FDA News Release. Silver Spring, MD: Food and Drug Administration; December 3, 2014.

11. Nagorsen D, Kufer P, Baeuerle PA, Bargou R. Blinatumomab: A historical perspective. Pharmacol Ther. 2012;136:334-342.

12. Klinger $\mathrm{M}$, Brandl $\mathrm{C}$, Zugmaier $\mathrm{G}$, et al. Immunopharmacologic response of patients with B-lineage acute lymphoblastic leukemia to continuous infusion of T cell-engaging CD19/CD3-bispecific BiTE antibody blinatumomab. Blood. 2012;119(26):6226-6233.

13. Hoffmann P, Hofmeister R, Brischwein K, et al. Serial killing of tumor cells by cytotoxic $T$ cells redirected with a CD19-/CD3bispecific single-chain antibody construct. Int J Cancer. 2005;115(1): 98-104.

14. Zugmaier G, Topp MS, Alekar S, et al. Long-term follow-up of serum immunoglobulin levels in blinatumomab-treated patients with minimal residual disease-positive B-precursor acute lymphoblastic leukemia. Blood Cancer J. 2014;4:244.

15. Topp MS, Gökbuget N, Zugmaier G, et al. Phase II trial of the antiCD19 bispecific $\mathrm{T}$ cell-engager blinatumomab shows hematologic and molecular remissions in patients with relapsed or refractory B-precursor acute lymphoblastic leukemia. J Clin Oncol. 2014;32(36): 4134-4140.

16. Blincyto ${ }^{\circledR}$ (Blinatumomab) [package insert]. Thousand Oaks, CA: Amgen; 2014.

17. Topp MS, Kufer P, Gökbuget N, et al. Targeted therapy with the T-cellengaging antibody blinatumomab of chemotherapy-refractory minimal residual disease in B-lineage acute lymphoblastic leukemia patients results in high response rate and prolonged leukemia-free survival. J Clin Oncol. 2011;29(18):2493-2498.

18. Bargou R, Leo E, Zugmaier G, et al. Tumor regression in cancer patients by very low doses of a T-cell-engaging antibody. Science. 2008;321: 974-977.

19. Topp MS, Gökbuget N, Zugmaier G, et al. Long-term follow-up of hematologic relapse-free survival in a phase 2 study of blinatumomab in patients with MRD in B-lineage ALL. Blood. 2012;120(26): 5185-5187.

20. Ribera JM, Ferrer A, Ribera J, Genescà E. Profile of blinatumomab and its potential in the treatment of relapsed/refractory acute lymphoblastic leukemia. Onco Targets Ther. 2015;8:1567-1574. 
21. Topp MS, Gökbuget N, Stein AS, et al. Safety and activity of blinatumomab for adult patients with relapsed or refractory B-precursor acute lymphoblastic leukaemia: a multicentre, single-arm, phase 2 study. Lancet Oncol. 2015;16(1):57-66.

22. Teachey DT, Rheingold SR, Maude SL, et al. Cytokine release syndrome after blinatumomab treatment related to abnormal macrophage activation and ameliorated with cytokine-directed therapy. Blood. 2013; 121(26):5154-5157.

23. Oak E, Bartlett N. Blinatumomab for the treatment of B-cell lymphoma. Expert Opin Investig Drugs. 2015;24(5):715-724.

24. Amgen. Phase 2 trial of Blinatumomab in Philadelphia positive/BCRABL positive acute lymphoblastic leukemia. Available from: https:// clinicaltrials.gov/ct2/show/NCT02000427. Accessed January 19, 2016.
25. ECOG-Acrin Cancer Research Group. Combination chemotherapy with or without Blinatumomab in treating patients with newly diagnosed BCR-ABL-negative B lineage acute lymphoblastic leukemia. Available from: https://clinicaltrials.gov/ct2/show/NCT02003222. Accessed January 19, 2016.

26. Amgen. Phase 3 Trial of Blinatumomab Investigator's choice of chemotherapy in patients with relapsed or refractory ALL. Available from: https://clinicaltrials.gov/ct2/show/NCT02013167. Accessed January 19, 2016.

\section{Publish your work in this journal}

Therapeutics and Clinical Risk Management is an international, peerreviewed journal of clinical therapeutics and risk management, focusing on concise rapid reporting of clinical studies in all therapeutic areas, outcomes, safety, and programs for the effective, safe, and sustained use of medicines. This journal is indexed on PubMed Central, CAS,
EMBase, Scopus and the Elsevier Bibliographic databases. The manuscript management system is completely online and includes a very quick and fair peer-review system, which is all easy to use. Visit http://www.dovepress.com/testimonials.php to read real quotes from published authors.

Submit your manuscript here: http://www.dovepress.com/therapeutics-and-clinical-risk-management-journal 